\title{
JUDICIALIZAÇÃO DA POLÍTICA, PODER JUDICIÁRIO E COMISSÕES PARLAMENTARES DE INQUÉRITO NO BRASIL
}

\author{
Eduardo Meira Zauli
}

\begin{abstract}
RESUMO
A partir da noção de judicialização da política, procura-se discutir alguns aspectos das relações entre os Poderes Judiciário e Legislativo no Brasil no contexto de vigência da Constituição de 1988. Tendo como foco específico a problemática do controle de constitucionalidade e judicialização dos procedimentos adotados no âmbito das comissões parlamentares de inquérito, o artigo fundamenta-se em pesquisa sobre a jurisprudência do Supremo Tribunal Federal (STF) acerca do estatuto e das limitações constitucionais do trabalho das comissões parlamentares de inquérito no Congresso Nacional. Aborda-se a questão da separação de Poderes nas democracias contemporâneas, ilustrando o quanto as inter-relações entre os três ramos do Estado afastam-se, na prática, da formulação clássica da teoria; o que permite toda uma complexa teia de controles mútuos que constituem um campo fértil para a ascendência do poder Judiciário sobre o poder Legislativo e a referida judicialização da política.
\end{abstract}

PALAVRAS-CHAVE: judicialização da política; comissões parlamentares de inquérito; Brasil.

\section{INTRODUÇÃO: JUDICIALIZAÇÃO DA PO- LÍTICA}

O interesse dos cientistas políticos pelos aspectos legais do funcionamento das instituições não é algo propriamente novo. Há muito reconhece-se na magistratura um ator cujas decisões afetam de maneira importante a dinâmica da interação política em nossas sociedades. De maneira que as condicionantes, as características e as conseqüências dos processos de tomada de decisão no âmbito das instituições judiciais constituem os aspectos centrais de sua abordagem pela Ciência Política. Sumarizando os postulados básicos da literatura da Ciência Política sobre o assunto, Gibson (2006) sugere que "em suma, as decisões dos juízes são uma função do que eles preferem fazer, temperada pelo que eles pensam que deveriam fazer, mas constrangida pelo que eles percebem que é viável fazer" (idem, p. 515-516; tradução do autor). As variáveis independentes mencionadas informariam o cerne de diferentes abordagens teóricas no campo da Ciência Política. Assim, as preferências da magistratura seriam o foco privilegiado de um modelo de análise atitudinal; o que os magistrados deveriam fazer é a preocupação do modelo legal e da teoria dos papéis; enquanto a preocupação com a viabilidade das decisões judiciais é parte central de abordagens estratégicas.

Nos últimos anos, diante da constatação da expansão dos poderes judiciais nas democracias contemporâneas, tornou-se corrente entre os cientistas políticos o uso da expressão judicialização $d a$ política para referir-se à interferência de decisões judiciais e à introdução de procedimentos de natureza judicial em diversas arenas políticas. Assim, Vallinder (1995) propõe que a noção de judicialização da política envolve "(1) a expansão do campo dos tribunais ou dos juízes em detrimento dos políticos e/ou dos administradores, isto é, a transferência de poder de decisão do legislador, do governo, ou da administração civil para os tribunais ou, pelo menos, (2) a propagação dos métodos da tomada de decisão judicial para fora do campo judicial propriamente dito. Em resumo, podemos dizer que a judicialização envolve essencialmente uma transformação na direção do processo judicial" (idem, p. 13).

No mesmo tom, Tate (1995) define a judicialização da política como "1. o processo pelo qual os tribunais e juízes tendem a dominar cada vez mais a produção de políticas públicas já criadas (ou, acredita-se amplamente, que pelo menos deveriam ser criadas) por outras agências gover- 
namentais, especialmente legislativos e executivos, e 2. o processo pelo qual os fóruns de negociação e de tomada de decisão não judiciais tornam-se dominados por normas e procedimentos quasejudiciais (legalistas)".

$\mathrm{Na}$ experiência brasileira posterior à promulgação da Constituição de 1988 pode-se observar o desenvolvimento de ambos os processos de judicialização da política, sendo que em se tratando de investigar as relações entre o poder Judiciário e as comissões parlamentares de inquérito deve-se estar atento para ambas as perspectivas mencionadas anteriormente por Vallinder e Tate. Mais ainda, alguns dos fatores que respondem por tal fenômeno no Brasil assemelham-se àquelas condições que, segundo Tate (1995), facilitaram a expansão do poder judicial em outros sistemas democráticos: (i) a operação de um sistema político democrático; (ii) a existência de um ordenamento institucional baseado na separação de poderes; (iii) a existência de uma carta de direitos; (iv) o uso dos tribunais por grupos de interesse; (v) o uso dos tribunais pela oposição; (vi) a inefetividade das instituições majoritárias em impedir o envolvimento de instituições judiciais em certas disputas políticas; (vii) percepções negativas acerca das instituições majoritárias e legitimação de instituições judiciais; (viii) algum grau de delegação de poderes de decisão das instituições majoritárias em favor de instituições judiciais.

Contudo, outros fatores também contribuíram para a ocorrência de uma maior ascendência do poder Judiciário sobre o sistema político brasileiro: (i) em primeiro lugar, a promulgação de uma Constituição cujo caráter principiológico e programático, acompanhado de uma nova hermenêutica que confere normatividade aos valores e princípios constitucionais permitiu um processo de constitucionalização do Direito, no sentido da irradiação dos princípios e valores constitucionais por todo o sistema jurídico; abrindo espaço para uma releitura do Direito infraconstitucional e das decisões dos poderes Legislativo e Executivo à luz da Constituição (BARROSO, 2009), interpretada "[...] em torno de enunciados abertos, indeterminados e plurissignificativos - as fórmulas lapidares que integram a parte dogmática das constituições" (MENDES, COELHO \& BRANCO, 2008, p. 58); (ii) a ampliação do elenco de intérpretes da Constituição por meio da abertura do sistema de controle de constitucionalidade a um leque mais am- plo de atores legitimados para propor ações de constitucionalidade; (iii) as novas garantias de independência do poder Judiciário e do Ministério Público $^{1}$; (iv) os novos mecanismos de acesso ao poder Judiciário ${ }^{2}$; $(v)$ para além das condições mencionadas, observa-se no Brasil também certo descompasso entre os valores e orientações predominantes no âmbito das instituições majoritárias, por um lado, e os valores e orientações predominantes no âmbito das instituições judiciais, por outro. Assim, de uma combinação de ativismo judicial e choque de valores entre aqueles dois tipos de instituição a resultante tem sido o fenômeno da judicialização da política. "Mesmo sob uma constelação muito favorável de condições facilitadoras, o desenvolvimento atual da judicialização da política exige que os juízes tenham as atitudes pessoais e as preferências políticas ou valores apropriados, especialmente em relação aos valores de outros tomadores de decisão. De outro modo, em

${ }^{1}$ Com relação ao Ministério Público, seus membros foram equiparados à magistratura quanto às garantias da vitaliciedade, inamovibilidade e irredutibilidade de subsídio. Adicionalmente, suas funções foram ampliadas, fazendo que a instituição fosse legitimada, entre outras prerrogativas, para a promoção das ações civil pública e de inconstitucionalidade; componentes importantes do processo de ativação do poder Judiciário e de judicialização de diversos conflitos políticos (MAZZILLI, 1998; ARANTES 1999; VIANNA et alii, 1999; SILVA, 2001; PAES, 2003; KERCHE, 2007; CASAGRANDE, 2008). Nesse sentido o caso brasileiro assemelha-se à experiência italiana nas últimas décadas. Também na Itália o pubblico ministero, em virtude de sua posição institucional, vem desempenhando um papel decisivo na judicialização da política. Isso faz que a situação italiana afaste-se significativamente das experiências em curso em outras democracias, ao ponto de ser considerada por Di Federico (1995) como um caso peculiar. Quanto ao poder Judiciário italiano stricto sensu, a adoção de um elemento característico de sistemas de common Law (um maior grau de independência interna da magistratura) tem contribuído para a limitada autonomia do poder Judiciário frente às diversas forças políticas externas em um contexto marcado pelo aumento de sua importância política (GUARNIERI, 1995).

2 Pode-se destacar a criação e institucionalização dos juizados especiais; o novo estatuto das Defensorias Públicas; a ampliação do alcance do instituto da ação popular, além das novas prerrogativas processuais do Ministério Público. Tais mecanismos, dentre outras alterações do sistema de justiça do país, inserem-se no âmbito da adoção de uma Constituição "processual" que comporta uma série de instrumentos jurídicos que permitem a participação dos cidadãos em ações demandando a concretização dos direitos previstos no texto constitucional (CASAGRANDE, 2008). 
condições favoráveis a judicialização só se desenvolve porque os juízes decidem que devem (1) participar na elaboração de políticas que poderiam ser deixadas ao critério sábio ou tolo de outras instituições, e, pelo menos de vez em quando, (2) substituir as soluções políticas de outras instituições por soluções políticas próprias" (TATE, 1995, p. 33). "De juízes ativistas, por definição, pode-se esperar que aproveitem todas as oportunidades de utilizar suas decisões para disseminar os valores que lhes são caros. Mas quando esses valores são consistentes com os valores dominantes nas instituições majoritárias, haverá muito menos incentivos para que juízes ativistas tentem judicializar um processo político que já esteja produzindo aqueles resultados políticos, mesmo que as condições sejam favoráveis para fazê-lo ${ }^{3 "}$ (idem, p. 34).

Sintetizando as mudanças que têm permitido algum grau de minimização dos efeitos nocivos para a democracia brasileira do estreitamento da esfera pública decorrente da predominância do poder Executivo sobre um poder Legislativo insulado da sociedade civil, afirma Vianna: "Com efeito, a Carta de 1988 veio a redefinir as relações entre os Três Poderes, dando eficácia, entre nós, ao sistema do judicial review, principalmente quando admitiu personagens institucionais da sociedade civil na comunidade de intérpretes com direito à participação no controle da constitucionalidade das leis. A partir dessa inovação, segmentos organizados da sociedade civil passaram a gozar da faculdade de provocar a intervenção do Supremo Tribunal Federal (STF) no sentido de argüir a inconstitucionalidade de lei ou norma da Administração. Nessa mesma direção, constitucionalizou os institutos da ação popular e da ação civil pública, dando-lhes maior abrangência, recriou a figura do Ministério Público, incumbindo-lhe da defesa da ordem jurídica, do regime democrático e dos interesses sociais e individuais indisponíveis. Sob essa nova formatação institucional, pela via da procedimentalização da aplicação do Direito, tem sido possível criar um outro lugar de manifestação da esfera pública, decerto que ainda embrionário, na conexão do cida-

3 "Activist judges, by definition, may be expected to take every opportunity to use their decision-making to expand the policy values they hold dear. But when those values are consistent with the values dominating majoritarian institutions, there will be much less incentive for activist judges to seek to judicialize a political process that is already producing such good policy results, even though the conditions are favorable for doing so" (TATE, 1995, p. 34). dão e de suas associações com o poder Judiciário e que é capaz de atuar sobre o sistema político" (VIANNA, 2002, p. 11).

A amplitude do fenômeno é tamanha a ponto de permitir que se estabeleçam paralelos entre a situação dos Estados Unidos, captada pela análise de Tocqueville da democracia na América jacksoniana, e o cotidiano de muitos sistemas políticos da atualidade. "Quase não existe questão política, nos Estados Unidos, que cedo ou tarde não se resolva como questão judiciária. Daí a obrigação em que se acham os partidos, na sua polêmica quotidiana, de tomar emprestadas à justiça as idéias e a linguagem. [...] A linguagem jurídica se torna, assim, de certo modo, a língua vulgar; o espírito jurídico, nascido no interior das escolas e dos tribunais, propaga-se pouco a pouco para fora do seu recinto, infiltrando-se, por assim dizer, em toda a sociedade e descendo até as últimas fileiras; e o povo todo acaba por contrair uma parte dos hábitos e gostos do magistrado" (TOCQUEVILLE, 1987, p. 207-208).

\section{O ESQUEMA DA TRIPARTIÇÃO DOS PO- DERES NA CONSTITUIÇÃO DE 1988}

A moderna doutrina da separação de poderes do Estado que encontra em Montesquieu a formulação que se converterá em dogma constituci$\mathrm{onal}^{4}$ a partir do século XIX, remonta ao processo de afirmação do credo político liberal e sua preocupação central com a contenção dos poderes do Estado. Com efeito, diante dos riscos inerentes à concentração dos poderes do Estado, a técnica da separação de poderes emerge como mecanismo institucional central para a garantia dos direitos individuais 5 e pré-condição para o exercício de controles sobre o Estado.

4 Segundo Madison (1973, p.130), “[...] o oráculo sempre consultado e sempre citado nesta matéria é Montesquieu. Se ele não é autor do inestimável preceito de que falamos, pelo menos foi ele quem melhor o desenvolveu e quem o recomendou de uma maneira mais efetiva à atenção do gênero humano."

5 Em meio às controvérsias suscitadas pela utilização das expressões separação/divisão de poderes, separação-divisão de funções, são sugestivas as observações de Dallari (2003, p. 216) que podem ser interpretadas no sentido de que o uso daqueles termos ora decorre da preocupação com a limitação dos poderes e conseqüente proteção dos direitos individuais; ora da preocupação com a separação/divisão de funções visando garantir maiores níveis de eficácia e eficiência estatais. 
Tem-se aí uma doutrina que, uma vez transformada em princípio constitucional, influenciará de maneira decisiva todo o constitucionalismo moderno. De fato, "[...] o princípio da separação de poderes adquiriu um status de forma que virou substância no curso do processo de construção e de aprimoramento do Estado de Direito, a ponto de servir de pedra de toque para se dizer da legitimidade dos regimes políticos, como se infere do célebre artigo XVI da Declaração dos Direitos do Homem e do Cidadão, de 1789, onde se declara que não tem constituição aquela sociedade em que não estejam assegurados os direitos dos indivíduos, nem separados os poderes estatais" (MENDES, COELHO \& BRANCO, 2008, p. 155; grifos no original).

O princípio da separação de poderes estatais é um dos fundamentos de uma certa noção de Estado de Direito recepcionada pelo texto da Constituição de 1988 no Brasil. Assim como todas as constituições republicanas brasileiras anteriores, a Constituição de 1988 incorporou em seu arcabouço o princípio da separação de poderes estatais, dessa feita como cláusula pétrea. "São poderes da União, independentes e harmônicos entre si, o Legislativo, o Executivo e o Judiciário" (BRASIL, 2009a, art. $2^{\circ}$ ). "Não será objeto de deliberação a proposta de emenda tendente a abolir: [...] III - a separação dos Poderes" [...] (idem, art. 60, § 4, III).

Deve-se notar, entretanto, que a evolução da doutrina da separação de poderes do Estado terminou por produzir um resultado significativamente diverso daquele proposto por Montesquieu. Diante da necessidade da criação e manutenção de um certo equilíbrio entre os três poderes, em vez de um equilíbrio natural decorrente de uma rígida e excludente separação de poderes, a resultante foi uma complexa interação entre os órgãos integrantes de cada um dos três poderes na qual cada um dos poderes é chamado a desempenhar funções típicas e atípicas, ocorrendo, portanto, uma interseção entre os três poderes, em vez de uma completa separação de funções excludentes entre os diferentes ramos do Estado.

De fato, com o surgimento e posterior constitucionalização da doutrina dos freios e contrapesos 6 introduz-se nos modernos ordenamentos

\footnotetext{
6 Note-se que a formulação clássica da doutrina da separação dos poderes não comporta a institucionalização dos freios e contrapesos característicos dos ordenamentos jurí-
}

jurídicos mecanismos institucionais que configuram o que se convenciou chamar de transferência constitucional de competências ${ }^{7}$. A propósito, é nítida a linha de continuidade entre certas proposições relativas ao papel do poder Judiciário em $O$ Federalista e o teor da sentença da Suprema Corte norte-americana redigida pelo Juiz Marshall no leading case Marbury vs. Madison que, em 1803, foi um marco decisivo na inflexão da doutrina da separação de poderes.

Assim, sob o ordenamento de uma Constituição limitada ${ }^{8}$, pondera Hamilton: "Se me disserem que o corpo legislativo é constitucionalmente juiz dos seus poderes e que a maneira por que ele os interpretar fica tendo força de lei para os outros funcionários públicos, respondo que não é essa a presunção natural, quando a Constituição expressamente o não determina; porque não é possível que a Constituição tenha querido dar aos representantes do povo o direito de substituir a sua própria vontade à dos seus constituintes. Muito mais razoável é a suposição de que a Constituição quis colocar os tribunais judiciários entre o povo e a legislatura, principalmente para conter esta última nos limites das suas atribuições. A Constituição é e deve ser considerada pelos juízes como a lei fundamental; e como a interpretação das leis é a função especial dos tribunais judiciários, a eles pertence determinar o sentido da Constituição, assim como de todos os outros atos do corpo legislativo. Se entre estas leis se encontrarem algumas contraditórias, deve-se preferir aquela cuja observância é um dever mais sagrado; que é o mesmo que dizer que a Constituição deve ser preferida a um simples estatuto; ou a intenção do povo à dos seus agentes" (HAMILTON, 1973, p. 169).

Já o chief justice Marshall assim pronunciase: "Os poderes da legislatura são definidos e li-

dicos contemporâneos. Enquanto na primeira o equilíbrio entre os poderes é uma resultante natural da separação das várias funções do Estado entre seus três ramos (Executivo, Legislativo e Judiciário), a teoria dos freios e contrapesos supõe interferências recíprocas que relativizam a noção de independência entre os três poderes.

7 Por transferência constitucional de competência entende-se aqueles procedimentos que, amparados pelo texto constitucional, consistem na atribuição das funções típicas de cada um dos poderes aos outros, que as exercem atipicamente.

8 Madison (1973, p. 168) entende "Constituição limitada" como uma Constituição que limita a autoridade legislativa ordinária. 
mitados; para que esses limites não fossem mal compreendidos ou esquecidos a Constituição foi escrita. Com que propósito seriam os poderes limitados, e com que propósito essa limitação teria sido posta por escrito, se esses limites pudessem ser ultrapassados, a qualquer momento, por aqueles que pretendiam inibir? [...] É uma proposição muito evidente para ser contestada, a de que, ou a Constituição restringe todo ato legislativo que a contrarie, ou a legislatura pode alterar a Constituição por meio de um ato ordinário.

Entre essas alternativas não há meio termo. Ou a Constituição é uma lei superior, suprema, imutável por meios ordinários, ou se encontra no mesmo nível dos atos legislativos ordinários, e, como os outros atos, pode ser alterada quando a legislatura assim o desejar.

Se a primeira parte da alternativa é verdadeira, então um ato legislativo contrário à Constituição não é lei: se a última parte é verdadeira, então constituições escritas são tentativas absurdas por parte do povo para limitar um poder ilimitável em sua própria natureza" (UNITED STATES OF AMERICA, 1803).

Portanto, com relação à problemática das relações entre o poder Judiciário, por um lado, e os demais poderes de Estado, por outro, o aspecto central a ressaltar é o do princípio da supremacia da Constituição que está na origem da noção de rigidez constitucional e que se constitui em condição fundamental para o exercício, pelo poder Judiciário, de todo e qualquer controle de constitucionalidade de atos emanados dos poderes Executivo e Legislativo.

Introduzido um novo elemento na hierarquia das normas jurídicas, o princípio da supremacia da Constituição, diante de uma antinomia que oponha a Constituição a uma outra norma qualquer, a magistratura deve aplicar o critério hierárquico resolvendo o conflito em favor da prevalência da norma constitucional hierarquicamente superior ${ }^{9}$.

9 Tradicionalmente, os conflitos entre normas são resolvidos pela aplicação de três critérios: cronológico (prevalência da norma antinômica posterior em detrimento da anterior); hierárquico (prevalência da norma antinômica superior em detrimento da inferior) e de especialidade (prevalência da norma antinômica especial em detrimento da geral). No caso de conflitos de segundo grau, entre os critérios de superação das antinomias, o critério hierárquico prevalece sobre o cronológico; o da especialidade sobre o cronológico e o hierárquico sobre o da especialidade.

\section{FUNÇÕES DO PODER LEGISLATIVO FEDERAL NO BRASIL}

Em geral, do ponto de vista funcional os parlamentos são instituições polivalentes cujas funções extrapolam em muito o esquema clássico da separação entre os três poderes do Estado. Mesmo nos sistemas políticos alicerçados na tripartição clássica entre os ramos Executivo, Legislativo e Judiciário, os parlamentos estão longe de confinarem-se à função estritamente legislativa, embora esta seja a mais típica de suas funções, a ponto de fazer que os parlamentos sejam qualificados como poderes Legislativos (COTTA, 1992).

No caso brasileiro, o estatuto constitucional do poder Legislativo federal está contido no Título IV, “Da Organização dos Poderes”, Cap. I, “Do Poder Legislativo", artigos 44 a 75 da Constituição de 1988 (BRASIL, 2009a).

Quanto à sua função legislativa (típica), relativa à edição de atos normativos primários que instituem direitos e criam obrigações, o art. 44 estabelece: "O Poder Legislativo é exercido pelo Congresso Nacional, que se compõe da Câmara dos Deputados e do Senado Federal" (idem); sendo que as iniciativas que informam o processo legislativo $^{10}$ (emendas à Constituição; leis complementares; leis ordinárias; leis delegadas; medidas provisórias; decretos legislativos; resoluções) são elencadas no art. 59.

A função de controle e/ou de fiscalização (típica) encontra amparo em vários dispositivos constitucionais. O art. 49, por exemplo, confere ao Congresso Nacional uma competência genérica para fiscalizar e controlar o poder Executivo, incluída a administração indireta. O Artigo 58, § 3 , é a fonte de legitimidade constitucional para a realização de investigações pelas Comissões Parlamentares de Inquérito (CPIs). Já os artigos 70 a 74 tratam da prerrogativa do poder Legislativo de exercer a fiscalização contábil, financeira, orçamentária e patrimonial da União e das entidades da administração direta e indireta. O poder

\footnotetext{
10 O texto da Constituição de 1988 não faz distinção entre procedimento legislativo e processo legislativo. Assim, entende-se aqui por processo legislativo, o iter legis, que certos autores preferem qualificar como procedimento legislativo: "[...] uma sequência juridicamente preordenada de atividades de vários sujeitos na busca de um determinado resultado: a formação ou a rejeição da lei” (OLIVETTI, 1992, p. 996).
} 
Legislativo dispõe de mecanismos institucionais distintos por meio dos quais exerce suas prerrogativas de controle e/ou fiscalização: opera tanto por meio de comissões parlamentares (temporárias e permanentes) ${ }^{11}$ quanto por meio do Tribunal de Contas da União (TCU) ${ }^{12}$.

São funções administrativas (atípicas) do poder Legislativo federal a elaboração de seus regimentos, a provisão de cargos da sua estrutura, medidas relativas à sua organização administrativa etc. (BRASIL, 2009a, arts. 51 e 52). A função julgadora (atípica) relaciona-se com a prerrogativa de proceder ao julgamento de diversos agentes públicos com base em dispositivos constitucionais (arts. 52, I e II, e 55, § 2 e 3).

\section{ESTATUTO DAS COMISSÕES PARLAMEN-} TARES DE INQUÉRITO NO BRASIL

No âmbito federal, as CPIs são disciplinadas tanto pelo texto constitucional quanto pelos regimentos das casas legislativas federais no Brasil (2009c; 2009d). Com relação à Constituição brasileira, tais órgãos do poder Legislativo são objeto do $\S 3$ do seu artigo 58: "art. 58. O Congresso Nacional e suas Casas terão comissões permanentes e temporárias, constituídas na forma e com as atribuições previstas no respectivo regimento ou no ato de que resultar sua criação.

$\S 3^{\circ}$ As comissões parlamentares de inquérito, que terão poderes de investigação próprios das autoridades judiciais, além de outros previstos nos regimentos das respectivas Casas, serão criadas pela Câmara dos Deputados e pelo Senado Federal, em conjunto ou separadamente, mediante requerimento de um terço de seus membros, para a apuração de fato determinado e por prazo certo, sendo suas conclusões, se for o caso, encaminhadas ao Ministério Público, para que promova

11 Para uma análise calcada na preocupação com a efetividade das CPIs como mecanismos de controle sobre o poder Executivo, ver Figueiredo (2001) e Calcagnotto (2005). Para uma análise comparativa do funcionamento das comissões parlamentares das câmaras baixas na Argentina, Brasil, Chile e Uruguai ver Rocha e Barbosa (2008).

12 As competências do Tribunal de Contas da União estão elencadas no art. 71 da Constituição da República. No exercício do controle externo, o Congresso Nacional disporá do auxílio deste Tribunal cujos ministros " "...] terão as mesmas garantias, prerrogativas, impedimentos, vencimentos e vantagens dos Ministros do Superior Tribunal de Justiça” (BRASIL, 2009a, art. 73, § 3). a responsabilidade civil ou criminal dos infratores" (BRASIL, 2009a, art. 58).

As CPIs são ainda disciplinadas pelos regimentos da Câmara dos Deputados (câmara baixa com representação proporcional do eleitorado) e do Senado Federal (câmara alta/territorial com representação dos estados subnacionais através de eleições majoritárias). São também objeto do Regimento Comum do Congresso Nacional, que reúne aquelas duas casas legislativas.

Em seu art. 35, o Regimento da Câmara dos Deputados (BRASIL, 2009c) define o requisito constitucional do fato determinado para a criação de CPIs; da recepção do requerimento de criação de CPIs pelo Presidente da Câmara e de possível recurso à sua decisão ao Plenário da Câmara; do período de funcionamento das CPIs; da limitação de no máximo cinco CPIs funcionando concomitantemente; da composição numérica e da provisão dos meios necessários ao bom funcionamento das CPIs.

Em seu art. 36, o Regimento da Câmara dos Deputados trata da requisição de funcionários para a realização de trabalhos nas CPIs; da realização de diligências; oitiva de indiciados e inquisição de testemunhas; da requisição de informações e documentos de órgãos e entidades da administração pública e de serviços de quaisquer autoridades; da requisição de audiência de deputados e ministros de Estado; da tomada de depoimentos de autoridades públicas; da investidura de seus membros ou funcionários requisitados na realização de sindicâncias ou diligências; da realização de investigações e audiências públicas em todo o território nacional; dos prazos para atendimento das providências e realização das diligências definidas por CPI; da prerrogativa de, sendo diversos os fatos inter-relacionados e objetos do inquérito, pronunciar-se separadamente sobre cada um, mesmo antes de finda a investigação dos demais; da adoção das normas do Código de Processo Penal na condução dos trabalhos das CPIs.

No art. 37, há disposições relativas à apresentação, publicação e encaminhamento de relatório circunstanciado ao final dos trabalhos da CPI à Mesa da Câmara dos Deputados; ao Ministério Público ou à Advocacia-Geral da União; ao Poder Executivo; à Comissão parlamentar permanente afim à matéria investigada pela $\mathrm{CPI}$; à Comissão Mista de Planos, Orçamentos Públicos e Fiscalização; e ao Tribunal de Contas da União. 
O Regimento Interno do Senado Federal, em seu art. 145, disciplina o processo de criação de CPI, determinando que o requerimento de criação deste tipo de comissão contenha o fato determinado a ser apurado, o número de seus membros, o prazo de duração e o limite das despesas a serem realizadas pela comissão. Nesse mesmo artigo determina-se que cada Senador só poderá integrar duas CPIs, uma como titular, outra como suplente. O número de suplentes é fixado em número igual à metade do número dos titulares mais um.

Nos termos do art. 146, obsta-se a criação de CPI sobre matérias pertinentes à Câmara dos Deputados; às atribuições do poder Judiciário e aos estados.

O art. 148 explicita os poderes das CPIs: poderes de investigação próprios das autoridades judiciais, facultada a realização de diligências; a convocação de ministros de Estado; a tomada de depoimento de qualquer autoridade; a inquirição de testemunhas, sob compromisso; a oitiva de indiciados; a requisição de informações ou documentos a outros órgãos públicos; a requisição ao Tribunal de Contas da União da realização de inspeções e auditorias. Aplica-se o disposto no Código de Processo Penal relativamente à intimação de indiciados e testemunhas, e na inquirição de testemunhas e autoridades.

$\mathrm{O}$ art. 150 determina, ao término dos trabalhos da CPI, o envio de seu relatório e conclusões à Mesa Diretora do Senado Federal para conhecimento do Plenário.

Segundo o art. 151 a CPI encaminhará suas conclusões, se for o caso, ao Ministério Público, para que promova a responsabilidade civil ou criminal de possíveis infratores.

$\mathrm{O}$ art. 153 estabelece que nos diversos atos processuais, aplicar-se-ão, subsidiariamente, as disposições do Código de Processo Penal, sendo que, nos termos do art. 152, o prazo de funcionamento de CPI poderá ser prorrogado desde que não seja ultrapassado o período da legislatura em que for criada (art. 76).

Já o Regimento Comum do Congresso Nacional, em seu artigo 21 (BRASIL, 2009b), prescreve que as Comissões Parlamentares Mistas de Inquérito serão criadas em sessão conjunta das duas casas legislativas, requerendo-se a assinatura de um terço dos membros da Câmara dos De- putados mais um terço dos membros do Senado Federal. Tais comissões terão a participação de um número igual de deputados e senadores.

V. O SUPREMO TRIBUNAL FEDERAL E O CONTROLE JUDICIAL DO FUNCIONAMENTO E DOS ATOS DAS COMISSÕES PARLAMENTARES DE INQUÉRITO

Desde a promulgação da Constituição de 1988, o Supremo Tribunal Federal vem proferindo decisões que permitem diagnosticar um avanço do poder Judiciário no sentido do estreitamento dos mecanismos de controle judicial sobre as CPIs ${ }^{13}$.

Deixando de lado importantes decisões anteriores à vigência da Constituição de 1988 (GUIMARÃES, 1953) ${ }^{14}$, a competência jurisdicional originária do STF para o exercício do controle judicial sobre os atos praticados em CPIs no Congresso Nacional foi reafirmada em Mandado de Segurança, cuja decisão contém interpretação mais ampla do art. 102, I, da Constituição: “[...] a Comissão Parlamentar de Inquérito, enquanto projeção orgânica do Poder Legislativo da União, nada mais é senão a longa manus do próprio Congresso Nacional ou das Casas que o compõem, sujeitando-se, em consequência, em tema de mandado de segurança ou de habeas corpus, ao controle jurisdicional originário do Supremo Tribunal Federal [...]" (MELLO, 2000a).

Diante de uma representação em sede de mandado de segurança contra omissão atribuída à Mesa do Senado Federal, representada por seu Presidente, frustrando a instauração de inquérito parlamentar, assim manifestou-se o STF: "o controle jurisdicional de abusos praticados por Comissão Parlamentar de Inquérito não ofende o princípio da separação de poderes" (idem).

A essência do postulado da divisão funcional do poder, além de derivar da necessidade de conter os excessos dos órgãos que compõem o apa-

\footnotetext{
13 Tais decisões envolvem, em boa medida, um tratamento simétrico às CPIs do poder Legislativo federal, às CPIs no âmbito das Assembléias Legislativas estaduais, às CPIs na Câmara Legislativa distrital e às CPIs nas câmaras municipais; ainda que as prerrogativas das câmaras municipais tenham sofrido limitações adicionais decorrentes da inexistência de um poder Judiciário municipal, o que implica restrição ao requerimento de quebra de sigilo por parte das CPIs municipais. Ver Barbosa (2005).

14 Ver ainda Gallotti (1953).
} 
relho de Estado, representa o princípio conservador das liberdades do cidadão e constitui o meio mais adequado para tornar efetivos e reais os direitos e garantias proclamados pela Constituição.

Esse princípio, que tem assento no art. $2^{\circ}$ da Carta Política, não pode constituir e nem qualificar-se como um inaceitável manto protetor de comportamentos abusivos e arbitrários, por parte de qualquer agente do Poder Público ou de qualquer instituição estatal.

O Poder Judiciário, quando intervém para assegurar as franquias constitucionais e para garantir a integridade e a supremacia da Constituição, desempenha, de maneira plenamente legítima, as atribuições que lhe conferiu a própria Carta da República.

O regular exercício da função jurisdicional, por isso mesmo, desde que pautado pelo respeito à Constituição, não transgride o princípio da separação de poderes. "Desse modo, não se revela lícito afirmar, na hipótese de desvios jurídico-constitucionais nas quais incida uma CPI, que o exercício da atividade de controle constitucional possa traduzir situação de ilegítima interferência na esfera de outro Poder da República" (MELLO, 2005a). "A separação de poderes - consideradas as circunstâncias históricas que justificaram a sua concepção no plano da teoria constitucional - não pode ser jamais invocada como princípio destinado a frustrar a resistência jurídica a qualquer ensaio de opressão estatal ou a inviabilizar a oposição a qualquer tentativa de comprometer, sem justa causa, o exercício do direito de investigar, em sede de inquérito parlamentar, abusos que possam ter sido cometidos pelos agentes do Estado" (MELLO, 2005b).

O espectro das ações das CPIs está delimitado pelas competências constitucionais do Poder Legislativo. Assim, "podem ser objeto de investigação todos os assuntos que estejam na competência legislativa ou fiscalizatória do Congresso.

Se os poderes da Comissão Parlamentar de Inquérito são dimensionados pelos poderes da entidade matriz, os poderes desta delimitam a competência da comissão, ela não terá poderes maiores do que os de sua matriz. De outro lado, o poder da Comissão Parlamentar de Inquérito é coextensivo ao da Câmara dos Deputados, do Senado Federal e do Congresso Nacional" (BROSSARD, 1994).
Com relação ao objeto ou à amplitude do campo de atuação das CPIs o entendimento do art. $58, \S 3$ da Constituição pelo STF é no sentido de que a exigência de fato determinado "não impede a apuração de fatos conexos ao principal, ou ainda, de outros fatos, inicialmente desconhecidos, que surgirem durante a investigação" (MORAES, 2008, p. 419). "Tudo o que disser respeito, direta ou indiretamente, ao fato determinado que ensejou a Comissão Parlamentar de Inquérito pode ser investigado" (MENDES, COELHO \& BRANCO, 2008, p. 860). "A Comissão Parlamentar de Inquérito deve apurar fato determinado" (BRASIL, 2009a, art. 58, § 3). "Todavia, não está impedida de investigar fatos que se ligam, intimamente, com o fato principal" (VELLOSO, 1994).

Quanto à duração dos trabalhos das CPIs, em face da indefinição do texto do art. $58, \S 3^{\circ}$ da Constituição, definiu o STF que o término da respectiva sessão legislativa constitui-se no limite máximo para a prorrogação das atividades das CPIs $(\text { PERTENCE, 1994) })^{15}$. E isso não obstante o Regimento Interno da Câmara dos Deputados fixar o prazo máximo de duração dos trabalhos das CPIs em 120 dias, prorrogáveis por até 60 dias, mediante deliberação do Plenário. "A duração do inquérito parlamentar - com o poder coercitivo sobre particulares, inerente à sua atividade instrutória e a exposição da honra e da imagem das pessoas a desconfianças e conjecturas injuriosas - é um dos pontos de tensão dialética entre a CPI e os direitos individuais, cuja solução, pela limitação temporal do funcionamento do órgão, antes se deve entender matéria apropriada à lei do que aos regimentos: donde a recepção do art. $5^{\circ}, \S 2$, da Lei n. $1579 / 52$, que situa, no termo final de legislatura em que constituída, o limite intransponível de duração, ao qual, com ou sem prorrogação do prazo inicialmente fixado, se há de restringir a atividade de qualquer Comissão Parlamentar de Inquérito. A disciplina da mesma matéria pelo regimento interno diz apenas com as conveniências de administração parlamentar, das quais cada câmara é o juiz exclusivo, e da qual, por isso - desde que respeitado o limite máximo fixado em lei, o fim da legislatura em curso -, não decorrem direitos para terceiros, nem a legitimação para questionar em juízo sobre a interpretação que lhe dê a Casa do Congresso Nacional" (idem).

15 No mesmo sentido, cf. Pertence (2001) e Velloso (1996). 
Com base na previsão constitucional de requerimento de um terço dos membros da Câmara dos Deputados e/ou do Senado Federal para a criação de CPIs (BRASIL, 2009a, art. 58, § 3), o Supremo Tribunal Federal entende tal instituto como um direito das minorias parlamentares. Satisfeito aquele número mínimo de requerentes, há que se proceder à criação e instalação da respectiva CPI, direito subjetivo público das minorias parlamentares (MELLO, 2007). "O Parlamento recebeu dos cidadãos, não só o poder de representação política e a competência para legislar, mas, também, o mandato para fiscalizar os órgãos e agentes do Estado, respeitados, nesse processo de fiscalização, os limites materiais e as exigências formais estabelecidas pela Constituição Federal. O direito de investigar - que a Constituição da República atribuiu ao Congresso Nacional e às Casas que $o$ compõem (art. 58, §3) - tem, no inquérito parlamentar, o instrumento mais expressivo de concretização desse relevantíssimo encargo constitucional, que traduz atribuição inerente à própria essência da instituição parlamentar. A instauração do inquérito parlamentar, para viabilizar-se no âmbito das Casas legislativas, está vinculada, unicamente, à satisfação de três (03) exigências definidas, de modo taxativo, no texto da Carta Política [...]. Atendidas tais exigências (CR, art. 58, § 3), cumpre, ao Presidente da Casa legislativa, adotar os procedimentos subseqüentes e necessários à efetiva instalação da CPI, não the cabendo qualquer apreciação de mérito sobre o objeto da investigação parlamentar (...)" (MELLO, 2005b, s.p.).

$\mathrm{O}$ legislador constituinte atribuiu às CPIs no âmbito do Congresso Nacional "[...] poderes de investigação próprios das autoridades judiciais [...]" (BRASIL, 2009a, art. 58, § 3). Contudo, a jurisprudência do STF orienta-se no sentido da negação, às CPIs, dos poderes gerais de cautela titularizados pela magistratura.

Dentre os poderes de instrução assegurados às CPIs, está o de intimação de testemunhas e indiciados; podendo recorrer à condução coercitiva, caso necessário. Além de apresentar-se, é dever do convocado não "fazer afirmação falsa, ou negar ou calar a verdade como testemunha, perito, tradutor ou intérprete, perante a Comissão Parlamentar de Inquérito" (BRASIL, 1952).

Admite-se, contudo, na jurisprudência do STF, o privilégio do interrogando permanecer em silêncio para não se autoincriminar. Ademais, o direito de permanecer em silêncio é reconhecido pelo STF no caso de depoentes que estejam ao alcance do dever de sigilo profissional ${ }^{16}$.

Ainda com relação aos poderes instrutórios, as CPIs dispõem, dentre outras, da prerrogativa de quebra dos sigilos bancário, fiscal e de dados de seus investigados, além da determinação da realização de buscas e apreensões. Tais poderes, contudo, encontram limite em cláusula de reserva jurisdicional contida no texto constitucional ${ }^{17}$. Assim, diferentemente do que ocorre com outras informações sigilosas, a interceptação e conseqüente quebra do sigilo de comunicação telefônica estão submetidas à reserva de jurisdição, dependendo de ordem judicial. O mesmo ocorre com a busca e apreensão em domicílio de pessoa investigada por CPI (MENDES, COELHO \& BRANCO, 2008).

As CPIs estão impedidas também de decretar prisão, salvo nos casos de flagrância, decorrente de reserva jurisdicional, em situações não excepcionais, de decretar a privação da liberdade individual ${ }^{18}$.

16 Tal jurisprudência encontra amparo no art. $5^{\circ}$, LXIII da Constituição Federal: "o preso será informado de seus direitos, entre os quais o de permanecer calado, sendo-lhe assegurada a assistência da família e de advogado" (BRASIL, 2009); e na Convenção Americana Sobre Direitos Humanos, também conhecida como Pacto de San José da Costa Rica, de 1969, ratificada pelo Brasil em 1992: "Artigo $8^{\circ}$. Garantias judiciais. [...] 2. Toda pessoa acusada de um delito tem direito a que se presuma sua inocência, enquanto não for legalmente comprovada sua culpa. Durante o processo, toda pessoa tem direito, em plena igualdade, às seguintes garantias mínimas: [...]g) direito de não ser obrigada a depor contra si mesma, nem a confessar-se culpada [...]" (ORGANIZAÇÃO DOS ESTADOS AMERICANOS, 1969).

17 “Art. $5^{\circ}$ - XI - a casa é asilo inviolável do indivíduo, ninguém nela podendo penetrar sem consentimento do morador, salvo em caso de flagrante delito ou desastre, ou para prestar socorro, ou, durante o dia, por determinação judicial; [...] XII - é inviolável o sigilo da correspondência e das comunicações telegráficas, de dados e das comunicações telefônicas, salvo, no último caso, por ordem judicial, nas hipóteses e na forma que a lei estabelecer para fins de investigação criminal ou instrução processual penal" (BRASIL, 2009a).

18 "Ninguém será preso senão em flagrante delito ou por ordem escrita e fundamentada de autoridade judiciária competente, salvo nos casos de transgressão militar ou crime propriamente militar, definidos em lei" (BRASIL, 2009a, art. $\left.5^{\circ}, \mathrm{LXI}\right)$. 
Destaque-se também o impedimento de adoção de medidas cautelares, como a hipoteca judiciária, a indisponibilidade de bens, o arresto, $\mathrm{o}$ seqüestro, a proibição de ausentar-se do país etc. Segundo a interpretação predominante no STF acerca do alcance dos poderes de autoridade judicial conferidos às CPIs pela Constituição, tais medidas não são consideradas como instrutórias, âmbito ao qual se restringem seus poderes, por analogia com os poderes instrutórios de que dispõem os magistrados durante a instrução processual penal, e sim como medidas de provimento cautelar de eventual sentença futura, competência reservada aos membros do poder Judiciário (PERTENCE, 2000) $)^{19}$.

Outra limitação importante à ação dos membros das CPIs, também objeto de decisão do STF, é aquela que impede a proibição ou restrição à assistência jurídica aos convocados a comparecer, como testemunhas ou investigados, perante a CPI. Tendo o texto constitucional fixado em seu Título IV ("Da Organização dos Poderes"), Capítulo IV ("Das Funções Essenciais à Justiça"), o caráter essencial do exercício da advocacia para uma adequada prestação jurisdicional estatal ${ }^{20}$, entende o STF: “A Comissão Parlamentar de Inquérito, como qualquer outro órgão do Estado, não pode, sob pena de grave transgressão à Constituição e às leis da República, impedir, dificultar ou frustrar o exercício, pelo Advogado, das prerrogativas de ordem profissional que lhe foram outorgadas pela Lei n. 8 906/94. O desrespeito às prerrogativas que asseguram, ao Advogado, o exercício livre e independente de sua atividade profissional - constitui inaceitável ofensa ao estatuto jurídico da Advocacia, pois representa, na perspectiva de nosso sistema normativo, um ato de inadmissível afronta ao próprio texto constitucional e ao regime das liberdades públicas nele consagrado.

[...] assiste ao Advogado a prerrogativa - que lhe é dada por força e autoridade da lei - de velar pela intangibilidade dos direitos daquele que o constituiu como patrono de sua defesa técnica, competindo-lhe, por isso mesmo, para o fiel desem-

\footnotetext{
19 No mesmo sentido: Jobim (1999) e Gallotti (1999).

20 "O advogado é indispensável à administração da justiça, sendo inviolável por seus atos e manifestações no exercício da profíssão, nos limites da lei” (BRASIL, 2009a, art. 133).
}

penho do munus de que se acha incumbido esse profissional do Direito, o exercício dos meios legais vocacionados à plena realização de seu legítimo mandato profissional. O Advogado - ao cumprir o dever de prestar assistência técnica àquele que o constituiu, dispensando-lhe orientação jurídica perante qualquer órgão do Estado - converte, a sua atividade profissional, quando exercida com independência e sem indevidas restrições, em prática inestimável de liberdade. Qualquer que seja o espaço institucional de sua atuação, ao Advogado incumbe neutralizar os abusos, fazer cessar o arbítrio, exigir respeito ao ordenamento jurídico e velar pela integridade das garantias jurídicas legais ou constitucionais - outorgadas àquele que lhe confiou a proteção de sua liberdade e de seus direitos, dentre os quais avultam, por sua inquestionável importância, a prerrogativa contra a auto-incriminação e o direito de não ser tratado, pelas autoridades públicas, como se culpado fosse, observando-se, desse modo, diretriz consagrada na jurisprudência do Supremo Tribunal Federal" (MELLO, 2000b)

\section{CONCLUSÕES: HERMENÊUTICA CONS- \\ TITUCIONAL, DIREITOS E GARANTIAS FUNDAMENTAIS E PROCEDIMENTALI- ZAÇÃO DO DIREITO}

Na medida em que se entende a Constituição como um estatuto que consagra determinadas opções políticas tomadas pelo Soberano, a tarefa de interpretar o texto constitucional reveste-se inexoravelmente de um caráter político. Portanto, o Supremo Tribunal Federal desempenha um papel eminentemente político no exercício da jurisdição constitucional. "O caráter político da jurisdição é tanto mais forte quanto mais amplo for o poder discricionário que a legislação, generalizante por sua própria natureza, lhe deve necessariamente ceder. A opinião de que somente a legislação seria política - mas não a 'verdadeira' jurisdição - é tão errônea quanto aquela segundo a qual apenas a legislação seria criação produtiva do Direito, e a jurisdição, porém, mera aplicação reprodutiva. Trata-se, em essência, de duas variantes de um mesmo erro. Na media em que o legislador autoriza o juiz a avaliar, dentro de certos limites, interesses contrastantes entre si, e decidir conflitos em favor de um ou outro, está lhe conferindo um poder de criação do Direito, e portanto, um poder que dá à função judiciária o mesmo caráter 'político' que possui - ainda que em maior medida - a legis- 
lação. Entre o caráter político da legislação e o da jurisdição há apenas uma diferença quantitativa, não qualitativa" (KELSEN, 2003, p. 251).

Tendo como pressuposto a doutrina da separação de poderes, as transferências constitucionais de competências e os mecanismos de freios e contrapesos inseridos em nosso ordenamento jurídico, o controle judicial do funcionamento e dos atos das CPIs no Brasil sob a vigência da Constituição de 1988 tem sido exercitado a partir de uma nova hermenêutica constitucional pós-positivista assentada no reconhecimento da normatividade dos princípios constitucionais. "Procurando apontar os traços mais significativos desse novo constitucionalismo, concordam os estudiosos em caracterizá-lo pelas notas indicadas a seguir, expressivas o bastante para que o consideremos substancialmente distinto de todas as experiências constitucionais precedentes: a) mais Constituição do que leis; b) mais princípios do que regras; c) mais ponderação do que subsunção; e d) mais concretização do que interpretação" (MENDES, COELHO \& BRANCO, 2008, p. 126-127).

Com efeito, a partir da recepção pelo texto constitucional de certos direitos e garantias fundamentais ${ }^{21}$ associados ao princípio da dignidade da pessoa humana ${ }^{22}$, todos os poderes públicos vinculam-se ao conteúdo daqueles direitos e garantias. Com relação especificamente ao poder Legislativo: "Não há dúvida, portanto, de que os atos normativos do Poder Legislativo sujeitam-se aos direitos fundamentais, mas também outros atos desse Poder, com eficácia externa - atos de comissões parlamentares de inquérito, por exemplo -, não escapam à sujeição aos direitos fundamentais. Registre-se, a propósito, a jurisprudên-

21 Diferentemente do que ocorre com os chamados direitos humanos, por direitos fundamentais entende-se aqueles direitos tidos como inerentes à condição da dignidade da pessoa humana e que foram recepcionados pelo ordenamento jurídico de um Estado. Por direitos fundamentais entende-se, aqui, tanto os direitos quanto as garantias fundamentais. Para aqueles que procuram diferenciar essas duas categorias de normas, os direitos são disposições declaratórias, enquanto as garantias são assecuratórias (MENDES, COELHO \& BRANCO, 200; MORAES, 2008).

22 O princípio da dignidade da pessoa humana, como princípio fundamental da República Federativa do Brasil, encontra-se enunciado no Título I, art. $1^{\circ}$ da Constituição de 1988 (BRASIL, 2009a). cia com que o Supremo Tribunal Federal, em sede de habeas corpus ou de mandado de segurança, vem delimitando as deliberações de CPIs, em favor de postulados dos direitos fundamentais" (idem, p. 246).

Reafirmado pela Constituição de 1988, o princípio da jurisdição una e dada a consagração da tutela que assegura proteção judicial contra lesão ou ameaça a direito ${ }^{23}$, o Supremo Tribunal Federal tem sido acionado, especialmente em sede de habeas corpus ${ }^{24} \mathrm{e}$ de mandado de segurança, tendo em vista o controle judicial das CPIs. "No regime político que consagra o Estado Democrático de Direito, os atos emanados de qualquer Comissão Parlamentar de Inquérito, quando praticados com desrespeito à Lei Fundamental, submetem-se ao controle jurisdicional (CR, art. $5^{\circ}$, $\mathrm{XXXV)}$. As Comissões Parlamentares de Inquérito não têm mais poderes do que aqueles que lhes são outorgados pela Constituição e pelas leis da República. É essencial reconhecer que os poderes das Comissões Parlamentares de Inquérito precisamente porque não são absolutos - sofrem as restrições impostas pela Constituição da República e encontram limite nos direitos fundamentais do cidadão, que só podem ser afetados nas hipóteses e na forma que a Carta Política estabelecer" (MELLO, 2000a).

Desde a promulgação da Constituição de 1988, o papel do poder Judiciário como árbitro dos conflitos de interesses envolvendo os direitos e garantias fundamentais constitucionais vem sendo potencializado pelos vários fatores anteriormente mencionados. Longe de conformar-se ao papel de bouche de la loi, o exercício da prerrogativa de controle de constitucionalidade pelo poder Judiciário tem sido um elemento novo na dinâmica das relações assimétricas e desarmônicas entre os três poderes no Brasil. Corrobora-se assim uma

23 O chamado princípio da jurisdição una assumiu a seguinte forma: "a lei não excluirá da apreciação do Poder Judiciário lesão ou ameaça a direito (idem, art. $5^{\circ}, \mathrm{XXXV}$ ).

24 A propósito do surgimento da problemática do recurso ao poder Judiciário diante de decisões políticas que afetem direitos individuais sob o amparo do texto constitucional e da evolução da doutrina do habeas corpus (HC) no âmbito do ordenamento jurídico do Estado brasileiro, veja-se a célebre "Oração de Rui Barbosa perante o STF em 1892" (BARBOSA, 1892). Com relação ao contexto das decisões do STF em sede de habeas corpus por ocasião da impetração dos HC 300 (1892), 1063 e 1073 (1898), ver Costa (2006). 
situação que fez que os cientistas políticos propusessem que as instituições judiciárias fossem vistas como um subsistema do sistema político global: "[...] partilhando com este a característica de processarem uma série de inputs externos constituídos por estímulos, pressões, exigências sociais e políticas e de, através de mecanismos de conversão, produzirem outputs (as decisões) portadoras elas próprias de um impacto social e político nos restantes subsistemas.

[...] Uma tal concepção dos tribunais teve duas conseqüências muito importantes. Por um lado, colocou os juízes no centro do campo analítico. Os seus comportamentos, as decisões por eles proferidas e as motivações delas constantes, passaram a ser uma variável dependente cuja aplicação se procurou nas correlações com variáveis independentes, fossem elas a origem de classe, a formação profissional, a idade ou sobretudo a ideologia política e social dos juízes. A segunda conseqüência consistiu em desmentir por completo a idéia convencional da administração da justiça como uma função neutra protagonizada por um juiz apostado apenas em fazer justiça acima e eqüidistante dos interesses das partes" (SANTOS, 1995, p. 172-173).

Ainda que o tema do papel do poder Judiciário nas democracias contemporâneas seja algo eminentemente controverso entre os cientistas políticos (DREWRY, 1996), no caso específico do controle de constitucionalidade das CPIs o teor das decisões proferidas pelo STF, em vez de constituir um elemento prejudicial ao bom funcionamento do sistema democrático por suas supostas restrições ao poder do Soberano na ordem política nacional, pode ser tomado como indicador de que o poder Judiciário vem afirmando-se como uma nova arena para a defesa de direitos no âmbito da democracia brasileira. Nesse sentido, as linhas da interpretação constitucional trilhadas pelo STF na defesa dos direitos e garantias fundamentais encontrariam legitimação em suas conseqüências em termos da proteção das liberdades individuais, componente fundamental de uma noção de democracia que alcança o reconhecimento e a salvaguarda da titularidade, pelos cidadãos, de uma série de direitos individuais ${ }^{25}$.

25 Para uma síntese de diferentes argumentos relativos à legitimação democrática da interpretação constitucional sob a óptica de um cientista político, ver Shane (2006).
Assim, a judicialização da política no Brasil envolve um processo de procedimentalização ${ }^{26}$ do Direito que, ao permitir a participação dos cidadãos na produção do Direito contribui para que as decisões judiciais assimilem um caráter deliberativo que lhes proporciona níveis mais elevados de legitimidade procedimental. $\mathrm{O}$ que se passa com o poder Judiciário é uma mudança institucional que produz uma maior abertura desse poder à sociedade e contribui para o aprofundamento da dimensão participativa da democracia brasileira.

Ora, no que diz respeito mais diretamente ao Supremo Tribunal Federal, desde a promulgação da Constituição de 1988, uma das inovações participativas presentes na democracia brasileira foi a abertura do processo de interpretação constitucional pela via da ampliação da comunidade de intérpretes da Constituição por meio da legitimação de vários atores para a proposição de ações de caráter constitucional no STF 27.

Essa mesma abertura do STF aos influxos externos provenientes da sociedade manifesta-se por ocasião das diversas decisões proferidas no

26 O tema da procedimentalização do Direito é parte integrante da preocupação mais ampla com a formulação de uma teoria procedimental da democracia. Nesse registro, a fonte da legitimidade democrática do direito é a sua produção a partir de condições que atendam ao cânone democrático deliberativo. A propósito de uma abordagem do agir comunicativo com especial ênfase no direito nas sociedades democráticas, ver Habermas (2003).

27 "Podem propor a ação direta de inconstitucionalidade e a ação declaratória de constitucionalidade: I. O Presidente da República; II. A Mesa do Senado Federal; III. A Mesa da Câmara dos Deputados; IV. A Mesa de Assembléia Legislativa ou da Câmara Legislativa do Distrito Federal; V. O Governador de Estado ou do Distrito Federal; VI. O Procurador-Geral da República; VII. O Conselho Federal da Ordem dos Advogados do Brasil; VIII. Partido político com representação no Congresso Nacional; IX. Confederação sindical ou entidade de classe de âmbito nacional. $\S 1^{\circ} \mathrm{O}$ Procurador-Geral da República deverá ser previamente ouvido nas ações de inconstitucionalidade e em todos os processos de competência do Supremo Tribunal Federal. § $2^{\circ}$ Declarada a inconstitucionalidade por omissão de medida para tornar efetiva norma constitucional, será dada ciência ao Poder competente para a adoção das providências necessárias e, em se tratando de órgão administrativo, para fazê-lo em trinta dias. $\S 3^{\circ}$ Quando o Supremo Tribunal Federal apreciar a inconstitucionalidade, em tese, de norma legal ou ato normativo, citará, previamente, o AdvogadoGeral da União, que defenderá o ato ou texto impugnado" (BRASIL, 2009a, art. 103). 
âmbito daquele tribunal tendo como objeto as CPIs. Tanto o habeas corpus quanto o mandado de segurança configuram-se como direitos de proteção previstos pelo texto constitucional no Título dos Direitos e Garantias Fundamentais (art. $5^{\circ}$, LXVIII, LIX e LXX). Assim como ocorre por ocasião da proposição de uma ação direta de inconstitucionalidade, o que os legitimados a proporem ações de habeas corpus e mandado de segurança perante o STF demandam daquela Corte é uma declaração da inconstitucionalidade de eventuais atos praticados por membros de CPIs.

Enfim, o significado de tal abertura do Supremo perante a sociedade e de suas decisões relacionadas ao funcionamento das CPIs remete à noção de soberania complexa e suas repercussões sobre o exercício da cidadania nas sociedades democráticas contemporâneas. "[...] essa complexidade se faria presente pelo fenômeno emergente da pluralidade das formas expressivas da soberania [...]. Paralelamente, verifica-se que a pluralização da soberania tem coincidido com a ampliação dos níveis de representação, que passam a compreender, além dos representantes do povo por designação eleitoral, os que falam, agem e decidem em seu nome, como a magistratura e as diversas instâncias legitimadas pela lei a fim de exercer funções de regulação" (VIANNA \& BURGOS, 2002, p. 371).

Diante de lesão ou ameaça de lesão de um direito que lhe é assegurado pelo texto constitucional, o cidadão que representa contra membro de CPI perante o Supremo Tribunal Federal participa de um processo de procedimentalização da aplicação do Direito que, para além das instituições representativas de cunho eleitoral, permitelhe fazer-se representado em âmbito judicial em defesa de seus direitos e contribui para a legitimação democrática da jurisdição constitucional.

Edardo Meira Zauli (zauli@fafich.ufmg.br) é Doutor em Ciência Política pela Universidade de São Paulo (USP) e Professor de Ciência Política na Universidade Federal de Minas Gerais (UMFG).

\section{REFERÊNCIAS BIBLIOGRÁFICAS}

ARANTES, R. B. 1999. Direito e Política: o Ministério Público e a defesa dos direitos coletivos. Revista Brasileira de Ciências Sociais, São Paulo, v. 14, n. 39, p. 83-102, fev. Disponível em: http://www.scielo.br/scielo.php?pid= S0102-69091999000100005\&script $=$ sci_ arttext. Acesso em: 7.set.2011.

BARBOSA, R. 1892. Oração perante o Supremo Tribunal Federal, 23.abr. Disponível em: http:/ /pensadoresbrasileiros.home.comcast.net/ $\sim$ pensadoresbrasileiros/RuiBarbosa/oracao perante_o_stf.html. Acesso em: 7.set.2011.

BARBOSA, J. 2005. Ação Cível Originária n. 730, 22.set.Brasília: Supremo Tribunal Federal.

BARROSO, L. R. 2009. O novo Direito Constitucional e a constitucionalização do Direito. Aula Magna. TV Justiça, 21.fev. Disponível em: http://www.tvjustica.jus.br/videos/ AULA_MAGNA_Luis_Robeto_Barroso_21_02_09.wmv Acesso em: 7.set.2011.

BROSSARD, P. 1994. Habeas corpus n. 71 039-5. Brasília: Supremo Tribunal Federal.
CALCAGNOTTO, G. 2005. Comissões parlamentares de inquérito no Brasil e na Alemanha: semelhanças e diferenças. In: LLANOS M. \& MUSTAPIC, A. M. (orgs.). Controle parlamentar na Alemanha, na Argentina e no Brasil. Rio de Janeiro: Konrad.

CASAGRANDE, C. 2008. Ministério Público e a judicialização da Política. Porto Alegre: S. A. Fabris.

COSTA, E. V. 2006. O Supremo Tribunal Federal e a construção da cidadania. São Paulo: UNESP.

COTTA, M. 1992. Parlamento. In: BOBBIO, N; MATTEUCCI, N. \& PASQUINO, G. (orgs.). Dicionário de política. Brasília: UNB.

DALLARI, D. A. 2003. Elementos de teoria geral do Estado. 24a ed. São Paulo: Saraiva.

DI FEDERICO, G. 1995. Italy: A Peculiar Case. In: TATE, C. N. \& VALLINDER, T. (eds.) The Global Expansion of Judicial Power. New York: New York University. 
DREWRY, G. 1996. Political Instituions: Legal Perspectives. In: GOODIN, R. E. \& KLINGMANN, H.-D. (eds.). A New Handbook of Political Science. Oxford: Oxford University.

FIGUEIREDO, A. C. 2001. Instituições e política no controle do Executivo. Dados, Rio de Janeiro, v. 44, n. 4, p. 689-727. Disponível em:http://www.scielo.br/scielo.php? script $=$ sci_arttext\&pid=S0011-525820010004 00002 . Acesso em: 7.set.2011.

GALLOTTI, L. 1953. Mandado de Segurança $n$. 1 959, 23.jan. Brasília: Supremo Tribunal Federal.

1999. Mandado de Segurança n. 23 471, 10.nov. Brasília: Supremo Tribunal Federal.

GIBSON, J. L. 2006. Judicial Institutions. In: RHODES, R. A. W.; BINDER S. A. \& ROCKMAN, B. A. (eds.). The Oxford Handbook of Political Science. Political Institutions. Oxford: Oxford University.

GUARNIERI, C. 1995. Judicial Independence and Policy-Making in Italy. In: TATE, C. N. \& VALLINDER, T. (eds.). The Global Expansion of Judicial Power. New York: New York University.

GUIMARÃES, M. 1953. Recurso Ordinário em Habeas Corpus n. 32 678, 5.ago. Brasília: Supremo Tribunal Federal.

JOBIM, N. 1999. Mandado de Segurança n. 23 446, 18.ago. Brasília: Supremo Tribunal Federal.

HABERMAS, J. 2003. Direito e democracia: entre facticidade e validade. Rio de Janeiro: Tempo Brasileiro.

HAMILTON, A. 1973. O federalista. São Paulo: Abril Cultural.

KELSEN, H. 2003. Jurisdição constitucional. São Paulo: M. Fontes.

KERCHE, F. 2007. Autonomia e discricionariedade do Ministério Público no Brasil. Dados, Rio de Janeiro, v. 50, n. 2, p. 259-279. Disponível em: http://www.scielo.br/scielo. php? script=sci_arttext\&pid=S0011 52582007000200002 . Acesso em: 7.set.2011.

MADISON, J. 1973. O federalista. São Paulo: Abril Cultural.
MAZZILLI, H. N. 1998. O Ministério Público e a defesa do regime democrático. Revista de Informação Legislativa, Brasília, ano 35, $\mathrm{n}$. 138, p. 65-73, abr.-jun. Disponível em: http:// bdjur.stj.gov.br/xmlui/bitstream/handle/2011/ 22476/ministerio_publico_defesa_regime.pdf? sequence $=4$. Acesso em: 7.set.2011.

MELLO, C. 2000a. Mandado de Segurança n. 23 452-1, 12.maio. Brasília: Supremo Tribunal Federal.

2000b. Mandado de Segurança n. 23 576/ $D F$, 2.out. Brasília: Supremo Tribunal Federal.

2005a. Revista Trimestral de Jurisprudência n. 173/806. Brasília: Supremo Tribunal Federal.

2005b. Mandado de Segurança n. 24 831, 22.jun. Brasília: Supremo Tribunal Federal.

2007. Mandado de Segurança n. 26 441, 25.abr. Brasília: Supremo Tribunal Federal.

MENDES, G. F.; COELHO, I. M. \& BRANCO, P. G. G. 2008. Curso de Direito Constitucional. $2^{\text {a }}$ ed. São Paulo: Saraiva.

MORAES, A. 2008. Direito Constitucional. 23 ${ }^{\mathrm{a}}$ ed. São Paulo: Atlas.

OLIVETTI, N. 1992. Processo legislativo. In: BOBBIO, N; MATTEUCCI, N. \& PASQUINO, G. (orgs.). Dicionário de politica. Brasília: UNB.

PAES, J. E. S. 2003. O Ministério Público perante os Poderes Judiciário, Executivo e Legislativo. Análise de sua posição constitucional. Revista de Informação Legislativa. Brasília, ano 40, n. 159, p. 199-217, jul.-set. Disponível em: http://www.egov.ufsc.br/portal/sites/default/files/anexos/15701-15702-1PB.pdf. Acesso em: 7.set.2011.

PERTENCE, S. 1994. Habeas corpus n. 71 261, 11.maio. Brasília: Supremo Tribunal Federal.

2000. Mandado de Segurança n. 23 480, 4.maio. Brasília: Supremo Tribunal Federal.

2001. Habeas corpus n. 71 193, 23.mar. Brasília: Supremo Tribunal Federal.

ROCHA, M. M. \& BARBOSA, C. F. 2008. Regras, incentivos e comportamento: as comissões parlamentares nos países do Cone Sul. 
Revista de Sociologia e Política, Curitiba, v. 16, n. sup., p. 93-104, ago. Disponível em: http://www.scielo.br/scielo.php?pid=S0104$44782008000300007 \&$ script $=$ sci_arttext. Acesso em: 7.set.2011.

SANTOS, B. S. 1995. A Sociologia dos Tribunais e a Democratização da Justiça. In: . Pela mão de Alice: o social e o político na pósmodernidade. São Paulo: Cortez.

SHANE, P. M. 2006. Analyzing Constitutions. In: RHODES, R. A. W.; BINDER, S. A. \& ROCKMAN, B. A. (eds.). The Oxford Handbook of Political Science. Political Institutions. Oxford: Oxford University.

SILVA, C. A. 2001. Promotores de Justiça e novas formas de atuação em defesa de interesses sociais e coletivos. Revista Brasileira de Ciências Sociais, São Paulo, v. 16, n. 45, p. 127-144, fev. Disponível em: http:// www.scielo.br/scielo.php? pid=S0102$69092001000100007 \&$ script $=$ sci arttext. Acesso em: 7.set.2011.

TATE, C. N. 1995. Why the Expansion of Judicial Power? In: TATE, C. N. \& VALLINDER, T. (eds.). The Global Expansion of Judicial Power. New York: New York University.

TOCQUEVILLE, A. 1987. A democracia na América. São Paulo: USP.

VALLINDER, T. 1995. When the Courts Go Marching. In: TATE, C. N. \& VALLINDER, T. (eds.). The Global Expansion of Judicial Power. New York: New York University.

VELLOSO, C. 1996. Habeas corpus n. 71231. Brasília: Supremo Tribunal Federal.

VIANNA, L. W. 2002. Apresentação. In: VIANNA, L. W. (org.). A democracia e os três poderes no Brasil. Belo Horizonte: UFMG.

VIANNA, L. W. \& BURGOS, M. 2002. Revolução Processual do Direito e Democracia Progressiva. In: VIANNA, L. W. (org.). A democracia e os três poderes no Brasil. Belo Horizonte: UFMG

VIANNA, L. W.; CARVALHO, M. A. R.; MELO, M. P. C. \& BURGOS, M. B. 1999. A judicialização da política e das relações sociais no Brasil. Rio de Janeiro: Revan.

\section{OUTRAS FONTES}

BRASIL. 1952. Lei n. 1579 de 18 de abril, de 1952. Diário Oficial da União, 21.abr. Disponível em: http://www.jusbrasil.com.br/ legislacao/110141/lei-1579-52. Acesso em: 7.set.2011.

2009a. Constituição da República Federativa do Brasil. São Paulo: Saraiva.

. 2009b. Regimento Comum do Congresso Nacional. Disponível em: http://www. senado.gov.br/sf/. Acesso em: 7.set.2011.

2009c. Regimento Interno da Câmara dos Deputados. Disponível em: http://www2. camara.gov.br/internet/legislacao/legin.html/ visualizarTextoAtualizado? idNorma $=320110$. Acesso em: 10.maio.2009.
. 2009d. Regimento Interno do Senado Federal. Disponível em: http://www.senado. gov.br/sf/. Acesso em 10.maio.2009.

ORGANIZAÇÃO DOS ESTADOS AMERICANOS. 1969. Convenção Americana Sobre Direitos Humanos. Pacto de San José da Costa Rica, 22.nov, San José. Disponível em: http:/ /www.cidh.oas.org/Basicos/Portugues/ c.Convencao_Americana.htm. Acesso em: 7.set.2011.

UNITED STATES OF AMERICA. 1803. Marbury v. Madison, n. 5 U.S. (1 Cranch) 137; 2 L. Ed. 60. Washington (DC): Supreme Court of the United States. Disponível em: http:// www.constitution.org/ussc/005-137a.htm. Acesso em: 7.set.2011. 


\section{JUDICIALIZATION OF POLITICS, JUDICIARY POWER AND PARLIAMENTARY INVESTIGATION COMMISSIONS IN BRAZIL}

Eduardo Meira Zauli

Through the notion of the judicialization of politics, we discuss particular aspects of the relationship between the Judiciary and the Legislature in Brazil within the context of the 1988 Constitution. Taking the issue of control of constitutionality and the judicialization of procedures adopted within the ambit of parliamentary investigation commissions as our specific focus, this article is based on research on the jurisprudence of the Federal Appellate Court regarding the status and constitutional limitations of parliamentary investigation commissions within the National Congress. We look at the issue of the separation of powers in contemporary democracies, demonstrating just how distant the interrelations of the three branches of the State are, in practice, from the classical theoretical formulation; this allows for a complex web of mutual controls that make for fertile terrain for the primacy of Judiciary Power over Legislative Power and the above-mentioned judicialization of politics.

KEYWORDS: judicialization of politics; parliamentary research commissions; Brazil. 

LA JUDICIARISATION DE LA POLITIQUE, LE POUVOIR JUDICIAIRE ET LES
COMMISSIONS PARLEMENTAIRES D'ENQUÊTE AU BRÉSIL

Eduardo Meira Zauli

A partir de l'idée de judiciarisation de la politique, on cherche à discuter quelques aspects des relations entre les pouvoirs Judiciaire et Législatif au Brésil, dans le contexte de validité de la Constitution de 1988. En soulignant spécifiquement le problème du contrôle de la constitutionnalité et judiciarisation des procédures adoptées dans le domaine des commissions parlementaires d'enquête, l'article s'appuie sur la recherche sur la jurisprudence du Suprême Tribunal Fédéral (STF), autour du statut et des limitations constitutionnelles du travail des commissions parlementaires d'enquête dans le Congrès National. On aborde la question de la séparation des pouvoirs dans les démocraties contemporaines, en illustrant à quel point les interrelations entre les trois secteurs de l'Etat s'éloignent, en pratique, de la formulation classique de la théorie ; ce qui permet tout un réseau complexe de 
contrôles mutuels, qui constituent un domaine fertile pour l'ascension du Pouvoir Judiciaire sur le Pouvoir Législatif, et la judiciarisation évoquée de la politique.

MOTS-CLÉS: la judiciarisation de la politique ; les commissions parlementaires d'enquête ; le Brésil. 